\title{
Amperometric determination of dopamine N-doped graphene/Au@Pt core-shell nanoparticles modified glassy carbon electrode
}

\author{
Xianlan Chen ${ }^{1,2, a}$, Guowei Zhang ${ }^{1,2}$, Ling Shi ${ }^{1,2}$, Shanqin Pan ${ }^{1,2}$, Wei Liu*1,2,b, \\ Keqiang $\mathrm{Xu}^{1,2}$ \\ ${ }^{1}$ School of Science, Honghe University, \\ ${ }^{2}$ Key Laboratory of Natural Pharamaceutical \& Chemical Biology of Yunnan Province Mengzi, \\ Yunnan 661100, P.R.China \\ ae-mail: 13489086418@163.com, be-mail: liuwei4728@126.com
}

\begin{abstract}
Keywords: Nitrogen-doped graphene, Au@ Pt core-shell nanoparticles, NG/Au@Pt hybrid materials, Dopamine

Abstract. The formation of N-doped graphene (NG) use hydrothermal method with urea as reducing agent and nitrogen source. The surface elemental composition of the catalyst was analyzed through XPS, which showed the atomic ratio of N/C is $5.0 \%$, indicative of the effective N-doping. The Au@Pt core-shell nanoparticles were prepared by seed-mediated growth method, where tens of small Pt nanoparticles aggregated on gold seeds. Finally, the Au@ Pt core-shell nanoparticles was introduced into the interlayers of NG nanosheets to form Au@Pt/NG hybrid materials by sonication technique. The as-prepared Au@Pt/NG hybrid materials modified glassy carbon electrode ( $\mathrm{Au} @ \mathrm{Pt} / \mathrm{NG} / \mathrm{GCE}$ ) was first employed for the determination of DA. The DA oxidation current is linear to its concentration in the range of $6.0 \times 10^{-8} \sim 1.3 \times 10^{-6} \mathrm{M}$, and the detection limit was found to be $1.0 \times 10^{-8}(\mathrm{~S} / \mathrm{N}=3)$.
\end{abstract}

\section{Introduction}

Dopamine (DA) is one of the most important neurotransmitters in the nervous system, and an abnormal DA concentration in the brain may cause serious ailments such as Parkinson's disease and Schizophrenia [1]. A major obstacle encountered in monitoring DA with electrochemical methods in the real samples is the coexistence of high concentration of AA and UA, which oxidize at potential close to that of DA at bare conventional electrodes [2]. To overcome this problem, we report a new approach for the fabrication of nonenzymatic sensor based on Au@Pt/NG hybrid materials modified glassy carbon electrodes for determination of DA.

Theoretical studies revealed that doping graphene with nitrogen is effective to tailor its electronic property and chemical reactivity, because of the stronger electronegativity of nitrogen compared to that of carbon and conjugation between the nitrogen lone pair electrons and the graphene $\pi$-system [3]. In this paper, NG was prepared successfully by solvothermal synthesis process with urea as both reductant and nitrogen sources.

Metal nanoparticles are currently being designed to be introduced into the interlayers of graphene nanosheets to form NG-based hybrid materials, avoiding them from aggregating. Among the various nanocatalysts, Au-Pt alloy or core-shell structures have been widely explored by many scientists and engineers as the most effective catalysts for a variety of reactions [4]. In this paper, we employed a two-step strategy for synthesizing Au@Pt nanomaterial with core-shell structure as enhancing electrocatalyst. Finally, the Au@Pt was introduced into the interlayers of NG nanosheets to form Au@Pt/NG hybrid materials by sonication technique, which possess the favourable performance from both two counterparts and paves a new way to enhance the electrochemical properties for detecting DA.

\section{Experimental}

\section{Materials and apparatus}

Graphite powder $(99.95 \%, 325$ mesh) was obtained from Alfa Aesar (Tianjin, China). DA was 
obtained from J\&K Chemical Co. All other chemicals used were of analytical reagent grade. The UV-vis spectra (Perkin-Elmer Lambda 900 USA), the XPS analyses were carried out with ESCALAB250. Electrochemical measurements were recorded on a $\mathrm{CHI} 660 \mathrm{C}$ electrochemical analyzer (CHI, Shanghai).

\section{Preparation of $\mathbf{N}$-doped graphene}

NG was prepared by solvothermal synthesis process with urea as reductant and nitrogen source, the synthesis procedure as described below. First, Graphene oxide (GO) was synthesized by modified Hummers method [5]. Then, $60 \mathrm{~mL}$ of $\mathrm{GO}(0.5 \mathrm{mg} / \mathrm{mL})$ aqueous solution was placed into $150 \mathrm{~mL}$ beaker and then ultrasonicated for more than $3 \mathrm{~h}$, followed by the addition a certain amount of urea $\left(\mathrm{m}_{\mathrm{urea}} / \mathrm{m}_{\mathrm{GO}}=1: 30\right)$. The mixture was finally transferred to a $100 \mathrm{~mL}$ PTFE reactor equipped with magnetic stirring bars, and heated to $160{ }^{\circ} \mathrm{C}$ temperature for $3 \mathrm{~h}$.

\section{Preparation of Au@Pt core-shell nanoparticles}

$\mathrm{Au}$ nanoparticles were prepared according to Frens' method [6]. The Au@Pt core-shell nanoparticles were prepared by seed-mediated growth method. $2 \mathrm{~mL}$ of Au seeds were placed in the beaker, which contained $450 \mu \mathrm{L}$ of $1.0 \mathrm{mM} \mathrm{H}_{2} \mathrm{PtCl}_{4}$ and $660 \mu \mathrm{L}$ of water, the mixture was cooled down to ca. $4^{\circ} \mathrm{C}$. Then, $220 \mu \mathrm{L}$ of $10 \mathrm{mM} \mathrm{NaBH}_{4}$ was slowly dropped into beaker while stirring, the solution was stirred for another $30 \mathrm{~min}$.

\section{Results and discussion}

XPS analysis (Fig. 1) shows a predominant graphitic C 1s peak at ca. $285 \mathrm{eV}$, an O1s peak at ca. $532 \mathrm{eV}$ and N1s peak at ca. $410 \mathrm{eV}$. Moreover, the atomic ratio of N/C is $5.0 \%$ for NG, demonstrating nitrogen species have been successfully incorporated into graphene. Fig. 2 depicts the UV-vis spectral sequences of Au seeds and Au@Pd core-shell nanoparticles. It can be observed that a very pronounced gold characteristic peak $(\sim 510 \mathrm{~nm})$ is obtained. Nevertheless, $\mathrm{Pt}$ nanoparticles were deposited on the surface of $\mathrm{Au}$ seeds, the characteristic peak of $\mathrm{Au}$ seeds emerged to a small red shift, and a wide absorption peak of Pt from $300 \mathrm{~nm}$ to $700 \mathrm{~nm}$ is appear and the surface plasmon resonance peak of gold weakened. These spectral behaviors reasonably indicate the core-shell structure was successfully prepared, that is some of small Pt nanoparticles aggregated on Au seed, forming the Au@Pt core-shell nanostructures.

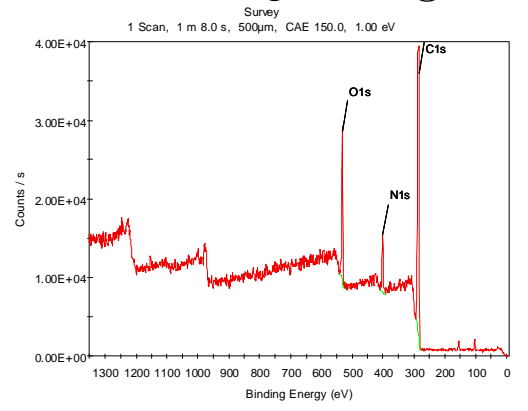

Fig. 1. XPS spectra of N-doped graphene.

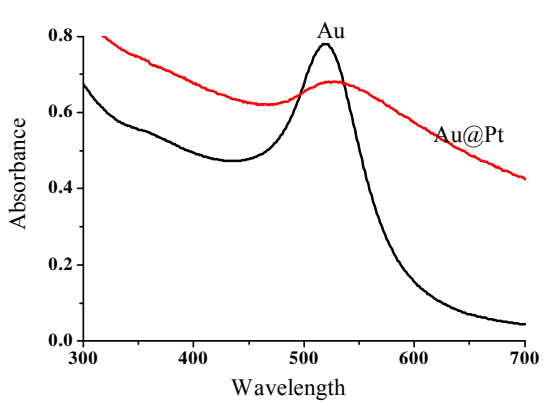

Fig. 2. UV-vis spectral sequences of Au seeds and Au@Pt core-shell nanoparticles.

The electrochemical behavior of DA is dependent on the $\mathrm{pH}$ value of an aqueous solution, so $\mathrm{pH}$ should be optimized for their catalytic determination. It is found that the peak current of DA increase with increasing $\mathrm{pH}$ value until it reaches 7.4 and decreases with a higher $\mathrm{pH}$ value in Fig. 3 . It is also found that the peak potential shifts positively with the increase of $\mathrm{pH}$. So pH $7.4 \mathrm{PBS}$ is chosen for DA determination. 


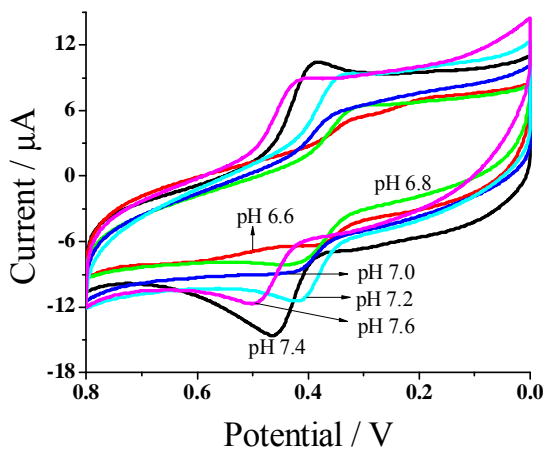

Fig. 3. $\mathrm{CVs}$ obtained at the $\mathrm{Au} @ \mathrm{Pt} / \mathrm{NG} / \mathrm{GCE}$ in PBS with different $\mathrm{pH}$ values $(6.6,6.8,7.0,7.2,7.4$ and 7.6) containing $20 \mathrm{mM}$ $\mathrm{DA}$ at scan rate of $50 \mathrm{mV} \mathrm{s}^{-1}$.

The effect of the scanning rate (v) on the peak current of DA was investigated by CV method. The dependence of oxidation peak current of $20 \mathrm{mM}$ DA on different scan rates at the $\mathrm{Au} @ \mathrm{Pt} / \mathrm{NG} / \mathrm{GCE}$ is illustrated in Fig. 4. As the scan rate increasing, the oxidation peak current $\left(\mathrm{I}_{\mathrm{pa}}\right)$ increases linearly with the scan rate in the range of $20 \sim 120 \mathrm{mV} \mathrm{s}^{-1}$, suggesting that the oxidation process is the adsorption-control.
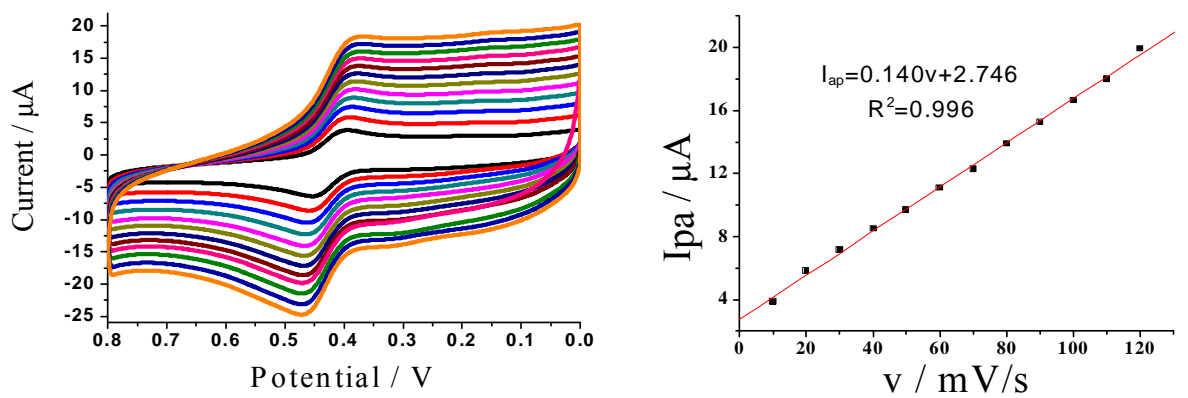

Fig. 4. CVs obtained at the $\mathrm{Au} @ \mathrm{Pt} / \mathrm{NG} / \mathrm{GCE}$ in $0.1 \mathrm{M}, 20 \mathrm{~mL}$ PBS (pH 7.4) at different scan rates $\left(20 \sim 120 \mathrm{mV} \mathrm{s}^{-1}\right)$ containing $20 \mathrm{mM}$ DA.

Fig. 5 illustrates the current-time plots for the present Au@Pt/NG/GCE under optimized conditions (at $0.4 \mathrm{~V}$ ) on successive addition of DA. Once DA was injected into the PBS blank, the modified electrode rapidly responds to change with the DA concentration. The linear relationship between the current and DA concentration is shown in Fig.5. As seen, the Au@Pt/NG/GCE displays a good linear response ranging from $6.0 \times 10^{-8} \sim 1.3 \times 10^{-6} \mathrm{M}$, and a detection limit of $1.0 \times 10^{-8} \mathrm{M}$ $(\mathrm{S} / \mathrm{N}=3)$.

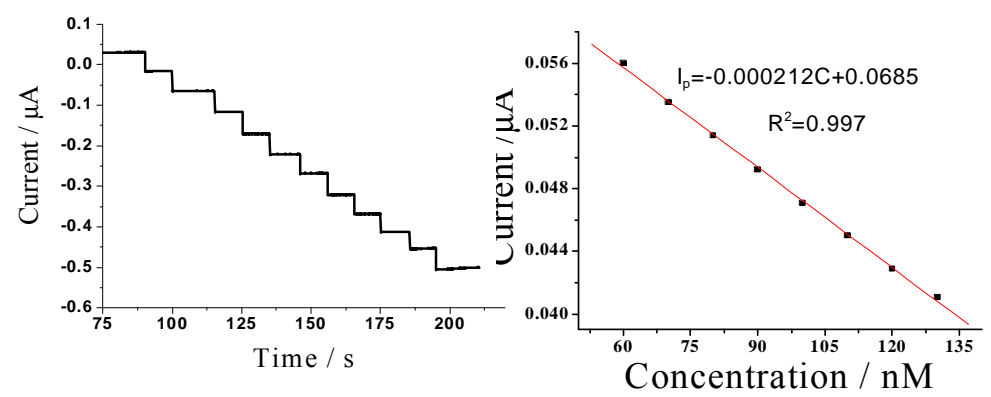

Fig. 5 (A) Typical amperometric current response of the $\mathrm{Au} @ \mathrm{Pt} / \mathrm{NG} / \mathrm{GCE}$ on successive injection of DA into stirring $\mathrm{N}_{2}$-saturated PBS (pH 7.4) at anapplied potential of $0.4 \mathrm{~V}$. (B) Calibration curve for DA concentration.

The reproducibility and stability of the sensor were evaluated. Five Au@Pt/NG/GCE were investigated in $50 \mathrm{mM}$ DA. The relative standard deviation (R.S.D.) is $2.6 \%$, confirming that the preparation method is highly reproducible. Stability of the modified electrode was tested by scanning the electrode continuously in $50 \mathrm{mM} \mathrm{DA}$, and it is found that there is no apparent decrease in the current response for 50 consecutive cycles (Fig. 6A), representing that the modified electrode is relatively stable. The selectivity of the Au@Pt/NG/GCE for detecting DA was also evaluated. Fig. $6 \mathrm{~B}$ shows the current responses of $0.5 \mathrm{mM}$ glucose, $0.5 \mathrm{mM} \mathrm{UA}, 0.5 \mathrm{mM} \mathrm{AA}, 0.5 \mathrm{mM} \mathrm{H}_{2} \mathrm{O}_{2}$ and $0.05 \mathrm{mM}$ DA on the $\mathrm{Au} @ \mathrm{Pt} / \mathrm{NG} / \mathrm{GCE}$ at $0.4 \mathrm{~V}$. As shown, the current responses of AA, UA, $\mathrm{H}_{2} \mathrm{O}_{2}$ and glucose observed are much smaller than those of DA, indicating the Au@Pt/NG/GCE has 
excellent selectivity for detecting DA.
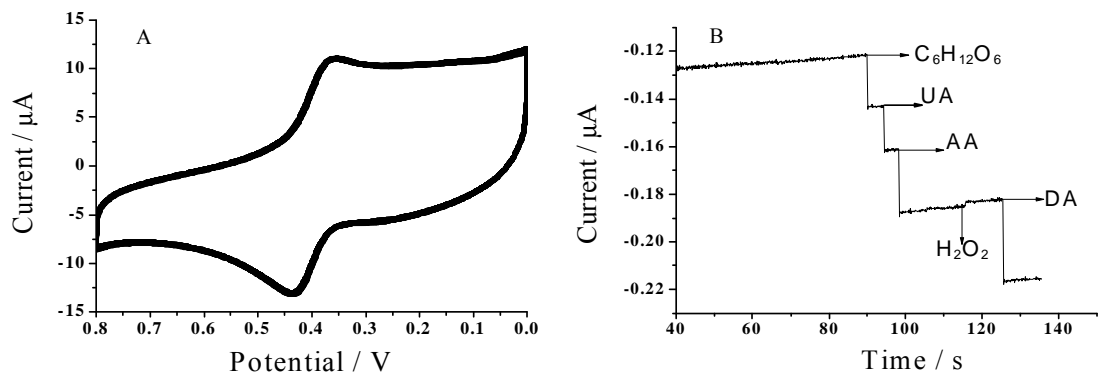

Fig. 6 (A) CVs of DA redox at the Au@Pt/NG/GCE in 0.1 M, 20 mL PBS (pH 7.4) containing 50 mM DA for 50 consecutive cycles. (B) Amperometric responses of $\mathrm{Au} @ \mathrm{Pd} / \mathrm{NG} / \mathrm{GCE}$ upon subsequent additions of $0.5 \mathrm{mM}$ glucose, $0.5 \mathrm{mM} \mathrm{UA}, 0.5 \mathrm{mM} \mathrm{AA}$, $0.5 \mathrm{mM} \mathrm{H}_{2} \mathrm{O}_{2}$ and $0.05 \mathrm{mM}$ DA e at $0.4 \mathrm{~V}$ vs. SCE.

\section{Conclusions}

A novel nonenzymatic DA sensor based on Au@Pt/NG hybrid materials modified glassy carbon electrodes was developed. The formation of NG use hydrothermal method with urea as reducing agent and nitrogen source. The Au@Pt core-chell nanoparticles were prepared by seed-mediated growth method, where tens of small Pt nanoparticles aggregated on gold seeds. Finally, the Au@Pt core-chell nanoparticles was introduced into the interlayers of NG nanosheets to form $\mathrm{Au} @ \mathrm{Pt} / \mathrm{NG}$ hybrid materials by sonication technique. The as-prepared Au@Pt/NG hybrid materials modified glassy carbon electrode ( $\mathrm{Au} @ \mathrm{Pt} / \mathrm{NG} / \mathrm{GCE})$ was first employed for the determination of DA. Electrochemical observation shows that the Au@Pt/NG/GCE has large active surface and high electrocatalytic activity for DA oxidation.

\section{Acknowledgments}

The authors gratefully acknowledge the financial support from the National Natural Science Foundation of China (61361002) and Yunnan Provincial Department of Education general Project (2013Y067).

\section{References}

[1] Y. J. Choi, J.-H. Choi, L. C. Liu, B.-K. Oh, S. Park, Chem. Mater. 25 (2013) 919.

[2] Y. Yue, G. Z. Hu, M. B. Zheng, Y. Guo, J. M. Cao, S. J. Shao, carbon 50 (2012) 107.

[3] G. X. Luo, L. Z. Liu, J. F. Zhang, G. B. Li, B. L. Wang, J. J. Zhao, 5 (2013) 11184.

[4] S. J. Guo, J. F. Zhai, Y. X. Fang, S. J. Dong, E. K. Wang, Chem. Asian J. 3 (2008) 1156.

[5] W. S. Hummers, R. E. Offeman, J. Am. Chem. Soc. 80 (1958) 1339.

[6] G. Frens, Nat. Phys. Sci. 241 (1973) 20. 